\title{
COVID-19 and the Gut Microbiome: More than a Gut Feeling
}

\author{
Daniel van der Lelie, a Safiyh Taghavi ${ }^{a}$
}

aGusto Global LLC, Morrisville, North Carolina, USA

ABSTRACT Due to its fundamental role in the induction, training, and function of the immune system, it is critical to include characterizations of the gut microbiome in clinical trials and studies that aim to broaden our understanding of coronavirus disease 2019 (COVID-19). Understanding the "gut-lung axes," where gut microbiome composition influences the lung's susceptibility to viral infections and viral infections of the lung alter gut microbiome composition toward proinflammatory functional dysbiosis, will be critical in addressing COVID-19, including disease progression, the importance of preexisting conditions, and the risk for developing complications. These insights may further help to develop better intervention strategies for COVID-19 and other diseases caused by respiratory viruses.

KEYWORDS COVID-19, gut microbiome

O ver the last 2 decades, three coronaviruses have emerged as causes for serious respiratory tract infections in humans: severe acute respiratory syndrome (SARS) caused by SARS coronavirus 1 (SARS-CoV-1), which emerged in late 2002 and disappeared by 2004; Middle East respiratory syndrome (MERS) caused by MERS-CoV, which emerged in 2012 and remains in circulation in camels; and coronavirus disease 2019 (COVID-19) caused by SARS-CoV-2, which emerged in December 2019 and has had considerable global economic and health impacts. Approximately $20 \%$ of patients with COVID-19 develop serious complications, especially an overactive immune response resembling cytokine storm syndrome (CSS) (1), often accompanied by fatal acute respiratory distress syndrome. Other serious or fatal complications of COVID-19 include hypercoagulation, and in young children a rare condition, multisystem inflammatory syndrome in children (MIS-C), that resembles Kawasaki disease (2).

Treatment and intervention strategies. Current treatment and intervention strategies being developed for COVID-19 focus on vaccine development for disease prevention, and in the absence of an approved vaccine, on treatment strategies that address viral replication or decrease the severity of complications caused by an overactive immune system. These strategies include remdesivir (Gilead Sciences), a nucleoside analogue that inhibits SARS-CoV-2 RNA-dependent RNA polymerase activity and viral replication (3), immune inhibitors, like the KEVZARA trial in which the efficacy of an anti-interleukin 6 (IL-6) receptor antibody is evaluated to stop an overactive inflammatory response, and development of monoclonal antibodies as therapy, as well as ongoing efforts with immediately available convalescent plasma (4). Also, type 1 interferons (especially alpha interferon [IFN- $\alpha$ ] and IFN- $\beta$ ) with broad antiviral activity are being evaluated in clinical trials to treat SARS-CoV-2 $(5,6)$. In vitro studies successfully confirmed the sensitivity of SARS-CoV-2 to type 1 interferons (7).

Respiratory viruses and the gut microbiome. The role of the gut microbiota in the severity of viral respiratory tract infections, such as those caused by the influenza virus (8), was recently recognized. Lung stroma were identified as the target of microbiotadriven signals (9) that set the type 1 interferon (IFN-I) signature in these cells as a defense against early viral infection. Influenza viruses replicate almost exclusively in the respiratory tract, yet infected individuals may also develop gastrointestinal (GI) symp-
Citation van der Lelie D, Taghavi S. 2020. COVID-19 and the gut microbiome: more than a gut feeling. mSystems 5:e00453-20. https:// doi.org/10.1128/mSystems.00453-20. Editor lleana M. Cristea, Princeton University Copyright $\odot 2020$ van der Lelie and Taghavi. This is an open-access article distributed under the terms of the Creative Commons Attribution 4.0 International license.

Address correspondence to Daniel van der Lelie,dvanderlelie@gustoglobal.com. Published 21 July 2020 
toms as observed for COVID-19 patients (10). These symptoms resulted from significantly changed gut microbiome composition through a mechanism dependent on type 1 IFN-I molecules. Notably, influenza-induced IFN-I molecules produced in the lung promoted depletion of obligate anaerobic bacteria and enrichment of Enterobacteriaceae in the gut, leading to a proinflammatory dysbiotic gut environment (11), further influencing virus infectivity. Changes to a proinflammatory gut microbiome have also been observed for other respiratory viruses, including adenovirus. Several commensal taxa essential for a healthy gut microbiome decreased, whereas genera containing potential pathogens, such as Neisseria, increased in abundance upon adenovirus infection in a lemur model (12). It should be noted that gut microbiome dysbiosis is often an underlying condition in patients suffering from diabetes, obesity, and autoimmune and aging-related diseases, the highest risk groups for severe COVID-19 (13), and that Gl symptoms are often indicative of severe COVID-19 complications.

A dysbiotic gut environment and epithelial inflammation increases levels of angiotensin-converting enzyme 2 (ACE2), a cell surface receptor that plays a key role in dietary amino acid homeostasis, innate immunity, and gut microbial ecology (14). ACE2 is the target of SARS-CoV-2 (15), and elevated ACE2 as found in patients characterized by a (preexisting) proinflammatory gut microbiome creates conditions favorable for infection by coronaviruses (16) like SARS-CoV-2 of the gut epithelium, from which it can further spread through the body (17). This is consistent with the development of Gl infections and detection of viral RNA in the feces of many COVID-19 patients, including those who tested negative by PCR of their respiratory secretions (18).

A unique subgroup of COVID-19 patients has been described as characterized by mild disease severity and marked by the presence of digestive symptoms. These patients were found to be more likely to test positive for viral RNA in stool, to have a longer delay before viral clearance, and to experience delayed diagnosis compared with patients with only respiratory symptoms (19). Prolonged digestive symptoms, especially diarrhea, are negatively associated with gut microbiota richness and composition (20), alterations that are closely associated with immune dysfunction, which might explain the delayed viral clearance. This implicates that reshaping the gut microbiota may be an adjuvant therapy in patients suffering from digestive symptoms linked to COVID-19.

A recent study from Wuhan, China, confirmed a link between gut microbiome composition and the predisposition of healthy individuals to COVID-19 (21). Increased levels of Lactobacillus species correlated to higher levels of anti-inflammatory IL-10 and improved disease prognosis; increased levels of proinflammatory bacterial species, including Klebsiella, Streptococcus, and Ruminococcus gnavus correlated with elevated levels of proinflammatory cytokines and increased disease severity. These species were previously found as enriched in the proinflammatory gut environment of patients suffering from a range of conditions, including diabetes, obesity, irritable bowel disease (IBD), and high blood pressure. Kawasaki disease, a condition similar to MIS-C that is increasingly reported as a complication in young children diagnosed with COVID-19 (2), is characterized by a dysbiotic gut microbiome with increased levels of Streptococcus and decreased levels of Lactobacillus species compared to healthy children (22). Therefore, COVID-19-induced changes in gut microbiome composition might contribute to this complication.

Discussion. A clear link may exist between gut microbiome health and COVID-19 progression. Understanding the "gut-lung axes," where gut microbiome composition influences the lung's susceptibility to viral infections and viral infections of the lung alter gut microbiome composition toward proinflammatory functional dysbiosis will be critical in addressing COVID-19, including disease progression, the importance of preexisting conditions, and the risk for developing complications. These insights will help to identify biomarkers and targets for drug development, and to develop intervention strategies based on live biotherapeutics and nutrition to overcome gut microbiome dysbiosis and restore intestinal homeostasis as contributing factors to COVID-19. 


\section{REFERENCES}

1. Moore JB, June CH. 2020. Cytokine release syndrome in severe COVID19. Lessons from arthritis and cell therapy in cancer patients point to therapy for severe disease. Science 368:473-474. https://doi.org/10 $.1126 /$ science.abb8925.

2. Jones VG, Mills M, Suarez D, Hogan CA, Yeh D, Segal JB, Nguyen EL, Barsh GR, Maskatia S, Mathew R. 2020. COVID-19 and Kawasaki disease: novel virus and novel case. Hosp Pediatr 10:537-540. https://doi.org/10.1542/ hpeds.2020-0123.

3. Gordon CJ, Tchesnokov EP, Feng JY, Porter P, Götte M. 2020. The antiviral compound remdesivir potently inhibits RNA-dependent RNA polymerase from Middle East respiratory syndrome coronavirus. J Biol Chem 295:4773-4779. https://doi.org/10.1074/jbc.AC120.013056.

4. Casadevall A, Pirofski L-A. 2020. The convalescent sera option for containing COVID-19. J Clin Invest 130:1545-1548. https://doi.org/10.1172/ JCl138003.

5. Belhadi D, Peiffer-Smadja N, Yazdanpanah Y, Mentré F, Laouénan C. 2020. A brief review of antiviral drugs evaluated in registered clinical trials for COVID-19. medRxiv https://doi.org/10.1101/2020.03.18.20038190.

6. Martinez MA. 2020. Compounds with therapeutic potential against novel respiratory 2019 coronavirus. Antimicrob Agents Chemother 64:e00399-20. https://doi.org/10.1128/AAC.00399-20.

7. Mantlo E, Bukreyeva N, Maruyama J, Paessler S, Huang C. 2020. Antiviral activities of type I interferons to SARS-CoV-2 infection. Antiviral Res 179:104811-104814. https://doi.org/10.1016/j.antiviral.2020.104811.

8. Bradley KC, Finsterbusch K, Schnepf D, Crotta S, Llorian M, Davidson S, Fuchs SY, Staeheli P, Wack A. 2019. Microbiota-driven tonic interferon signals in lung stromal cells protect from influenza virus infection. Cell Rep 28:245-256. https://doi.org/10.1016/j.celrep.2019.05.105.

9. Steed AL, Christophi GP, Kaiko GE, Sun L, Goodwin VM, Jain U, Esaulova E, Artyomov MN, Morales DJ, Holtzman MJ, Boon ACM, Lenschow DJ, Stappenbeck TS. 2017. The microbial metabolite desaminotyrosine protects from influenza through type I interferon. Science 357:498-502. https://doi.org/10.1126/science.aam5336.

10. Pan L, Mu M, Yang P, Sun Y, Wang R, Yan J, Li P, Hu B, Wang J, Hu C, Jin Y, Niu X, Ping R, Du Y, Li T, Xu G, Hu Q, Tu L. 2020. Clinical characteristics of COVID-19 patients with digestive symptoms in Hubei, China: a descriptive, cross-sectional, multicenter study. Am J Gastroenterol 115: 766-773. https://doi.org/10.14309/ajg.0000000000000620.

11. Deriu E, Boxx GM, He X, Pan C, Benavidez SD, Cen L, Rozengurt N, Shi W, Cheng G. 2016. Influenza virus affects intestinal microbiota and secondary Salmonella infection in the gut through Type I interferons. PLoS Pathog 12:e1005572. https://doi.org/10.1371/journal.ppat.1005572.

12. Wasimuddin, Corman VM, Ganzhorn JU, Rakotondranary J, Ratovonamana YR, Drosten C, Sommer S. 2019. Adenovirus infection is associated with altered gut microbial communities in a non-human primate. Sci Rep 9:e13410. https://doi.org/10.1038/s41598-019-49829-z.
13. Li N, Ma W-T, Pang M, Fan Q-L, Hua J-L. 2019. The commensal microbiota and viral infection: a comprehensive review. Front Immunol 10:e1551. https://doi.org/10.3389/fimmu.2019.01551.

14. Hashimoto $T$, Perlot $T$, Rehman $A$, Trichereau J, Ishiguro $H$, Paolino $M$ Sigl V, Hanada T, Hanada R, Lipinski S, Wild B, Camargo SMR, Singer D, Richter A, Kuba K, Fukamizu A, Schreiber S, Clevers H, Verrey F, Rosenstiel P, Penninger JM. 2012. ACE2 links amino acid malnutrition to microbial ecology and intestinal inflammation. Nature 487:477-481. https://doi.org/10.1038/nature11228.

15. Chan J-W, Kok K-H, Zhu Z, Chu H, To KK-W, Yuan S, Yuen K-Y. 2020. Genomic characterization of the 2019 novel human-pathogenic coronavirus isolated from a patient with atypical pneumonia after visiting Wuhan. Emerg Microbes Infect 9:221-236. https://doi.org/10.1080/ 22221751.2020.1719902.

16. Wang J, Zhao S, Liu M, Zhao Z, Xu Y, Wang P, Lin M, Xu Y, Huang B, Zuo $X$, Chen Z, Bai F, Cui J, Lew AM, Zhao J, Zhang Y, Luo H-B, Zhang Y. 2020 ACE2 expression by colonic epithelial cells is associated with viral infection, immunity and energy metabolism. medRxiv https://doi.org/10 $.1101 / 2020.02 .05 .20020545$

17. Zhou J, Li C, Zhao G, Chu H, Wang D, Yan HH-N, Poon VK-M, Wen L, Wong BH-Y, Zhao X, Chiu MC, Yang D, Wang Y, Au-Yeung RKH, Chan IH-Y, Sun S, Chan JK-W, To KK-W, Memish ZA, Corman VM, Drosten C, Hung IF-N, Zhou Y, Leung SY, Yuen K-Y. 2017. Human intestinal tract serves as an alternative infection route for Middle East respiratory syndrome coronavirus. Sci Adv 3:eaao4966. https://doi.org/10.1126/ sciadv.aao4966

18. Xiao F, Tang M, Zheng X, Liu Y, Li X, Shan H. 2020. Evidence for gastrointestinal infection of SARS-CoV-2. Gastroenterology 158: 1831-1833. https://doi.org/10.1053/j.gastro.2020.02.055.

19. Han C, Duan C, Zhang S, Spiegel B, Shi H, Wang W, Zhang L, Lin R, Liu J, Ding Z, Hou X. 2020. Digestive symptoms in COVID-19 patients with mild disease severity: clinical presentation, stool viral RNA testing, and outcomes. Am J Gastroenterol 115:916-923. https://doi.org/10.14309/ ajg.0000000000000664.

20. Vandeputte D, Falony G, Vieira-Silva S, Tito RY, Joossens M, Raes J. 2016. Stool consistency is strongly associated with gut microbiota richness and composition, enterotypes and bacterial growth rates. Gut 65:57-62. https://doi.org/10.1136/gutjnl-2015-309618.

21. Gou W, Fu Y, Yue L, Chen G-D, Cai X, Shuai M, Xu F, Chen H, Zhu Y, Xiao M-L, Jiang Z, Miao Z, Xiao C, Shen B, Wu X, Zhao H, Ling W, Wang J, Chen Y-M, Guo T, Zheng J-S. 2020. Gut microbiota may underlie the predisposition of healthy individuals to COVID-19. medRxiv https://doi.org/10 .1101/2020.04.22.20076091.

22. Esposito S, Polinori I, Rigante D. 2019. The gut microbiota-host partnership as a potential driver of Kawasaki syndrome. Front Pediatr 7:124. https://doi.org/10.3389/fped.2019.00124. 